\title{
Beachrock de Jaconé, Maricá e Saquarema - RJ: importância para a história da ciência e para o conhecimento geológico
}

\author{
Kátia Leite Mansur1, Renato Rodriguez Cabral Ramos², José Marcus de Oliveira Godoy ${ }^{3}$ \\ \& Vitor Manuel Rodrigues do Nascimento ${ }^{4}$
}

\begin{abstract}
Resumo Para resgatar os episódios vividos por Charles Darwin no estado do Rio de Janeiro e que fizeram parte da sua formação científica a bordo do Beagle, está em execução o Projeto Caminhos de Darwin. Em sua vertente geológica, estão sendo descritos, para fins de geoconservação, os afloramentos por ele descritos. $\mathrm{O}$ beachrock de Jaconé foi identificado pelo naturalista, então com 23 anos de idade, em 9 de abril de 1832. Com o passar dos anos e com pesquisas arqueológicas realizadas na região foram descobertos seixos de beachrock nos sambaquis da Beirada e de Moa, em Saquarema, mostrando que este material já era conhecido do homem pré-histórico há mais de 4000 anos A.P. No presente estudo, buscou-se realizar o enquadramento destas exposições como patrimônio geológico e, ao mesmo tempo, atualizar o conhecimento sobre sua geologia. Foram identificadas 3 litofácies e duas delas foram analisadas petrograficamente. Suas conchas foram datadas em 8198 - 7827 cal BP, pelo método radiocarbono. Concluiu-se que é inegável seu valor e que se constitui em patrimônio geológico, seja por sua importância histórica e cultural, seja pelas informações geológicas que pôde fornecer. A ocorrência se constitui como patrimônio geológico do tipo geomorfológico, sedimentar, paleoambiental, petrológico, além de arqueológico e contextualizado na história da ciência. Tem importância internacional e valor científico, cultural, didático e ecológico.
\end{abstract}

Palavras-chave: Patrimônio Geológico, História da Ciência, Beachrock, Darwin.

\begin{abstract}
The beachrock Jaconé, Maricá and Saquarema - RJ: importance to the history of science and to the geological knowledge. The Caminhos de Darwin Project aims to redeem the episodes experienced by Charles Darwin in the state of Rio de Janeiro and that they have had part in his scientific training aboard the Beagle. In the geological approach of this project, the outcrops described by Darwin in the State of Rio de Janeiro are being described with purposes of geoconservation. The beachrock of Jaconé was identified by the naturalist, at then 23 years old, on April 9, 1832. Over the years, archaeological researches conducted in the region discovered pebbles of beachrock in the middens of Beirada and Moa. This fact demonstrates that this rock was already known by prehistoric men for over 4000 years BP. The present study aimed to assess these outcrops as geological heritage and, at the same time, update the knowledge about its geology. Three lithofacies were identified and two of them were analyzed petrographically. The age of the shells was calculated at 8198$7827 \mathrm{cal}$ BP by the radiocarbon method. The occurrence is constituted as a geological heritage of the following typologies: geomorphological, sedimentary, paleoenvironmental, petrological, and archaeological and, also, contextualized in the science history. It has international significance and scientific, cultural, educational and ecological value.
\end{abstract}

Keywords: Geological Heritage, Science History, Beachrock, Darwin.

INTRODUÇÃO Beachrocks são depósitos sedimentares de praia cimentados pela precipitação em geral carbonática e cuja litificação usualmente se dá na zona intermarés. Podem envolver sedimentos de origem clástica ou bioclástica, nas frações granulométricas que variam de areia até bloco (Vousdoukas et al. 2007, Kelletat 2006). São também chamados de arenitos de praia e, na região Nordeste do Brasil, recebem o nome de arrecifes. Podem ser friáveis ou bem cimentados (Bates \& Jackson 1987), sendo que a cimentação pode ocorrer em poucos anos. Charles Darwin (1844) descreveu em Cabo Verde um conglomerado recente muito duro que possuía incrustado um parafuso de ferro entre seixos de basalto e cimento carbonático. Vale ressaltar que o arquipélago foi descoberto em 1460 (http://www.governo.cv/).

1 - Departamento de Geologia, Instituto de Geociências, Universidade Federal do Rio de Janeiro, Rio de Janeiro (RJ), Brasil. E-mail: katia@geologia.ufrj.br

2 - Departamento de Geologia e Paleontologia, Museu Nacional, Universidade Federal do Rio de Janeiro, Rio de Janeiro (RJ), Brasil.

E-mail: rramos@mn.ufrj.br

3 - Instituto de Radioproteção e Dosimetria, Rio de Janeiro (RJ), Brasil. E-mail: jmgodoy@ird.gov.br

4 - Instituto do Noroeste Fluminense de Educação Superior, Universidade Federal Fluminense, Santo Antônio de Pádua (RJ), Brasil.

E-mail: vitorgeotao@vm.uff.br 
Inicialmente, acreditava-se que beachrocks eram característicos de costas tropicais e subtropicais. No entanto, sabe-se hoje que as condições para sua cimentação podem ocorrer também em climas temperados e frios, como na região que vai de Santa Catarina até a Terra do Fogo, na Argentina (Martins et al. 2005a, 2005b). Segundo levantamento realizado por Vousdoukas et al. (2007), a formação dos beachrocks é um fenômeno global e diacrônico e as idades obtidas para os beachrocks estudados pelos autores situam-se principalmente entre 1000 e 5000 anos A.P.

A origem dos beachrocks tem sido objeto de muitos estudos e quatro mecanismos são os mais relatados para sua cimentação (Vousdoukas et al. 2007): (a) direta por precipitação a partir de águas marinhas e meteóricas e spray marinho; (b) precipitação de cimento devido à mistura de água doce e salgada no lençol freático costeiro; (c) precipitação de cimento devido à perda de $\mathrm{CO}_{2}$ da água subterrânea nos ambientes costeiros; e (d) por processos biológicos. Estas teorias explicam localmente cada caso estudado, mas não produzem uma ideia unificada para a origem dos beachrocks, onde a precipitação do cimento parece ser controlada por vários parâmetros ambientais físico-químicos, biológicos e hidrodinâmicos.

\section{PRIMEIRAS DESCRIÇÕES DE BEACHROCKS}

NO BRASIL As primeiras ocorrências de beachrock descritas na literatura mundial são as de Beauford (1817), Von Bush (1825), Moresby (1835), Darwin (1841) e Dana (1849) (in Vousdoukas et al. 2007).

Em 1841, Charles Darwin publicou o trabalho "On a remarkable bar of sandstone off Pernambuco, on the coast of Brazil", considerado o primeiro trabalho científico sobre beachrocks brasileiros. Darwin passou pelo Brasil de fevereiro a julho de 1832 e em agosto de 1836, quando de sua viagem ao redor do mundo a bordo do HMS Beagle. Nas oportunidades descreveu beachrocks e recifes de coral. Em suas cadernetas de campo (Freeman 1977) fez anotações sobre as ocorrências da Bahia $(1832,1836)$ e Pernambuco (1836).

Na publicação sobre recifes de coral, uma obra pioneira e até hoje considerada correta do ponto de vista da origem geológica dos atóis, Darwin (1842) assim descreve os beachrocks brasileiros: "The coast of Brazil is in many parts fringed by reefs. Of these, some are not of coral formation; for instance those near Bahia, and in front of Pernambuco; but a few miles south of this latter city, the reef follows [...] so closely every turn of the shore, that I can hardly doubt it is of coral: it runs at the distance of three quarters of a mile from the land, and within it the depth is from ten to fifteen feet. I was assured by an intelligent pilot, that at Ports Frances and Maceio, the outer part of the reef consists of living coral, and the inner of a white stone, full of large irregular cavities, communicating with the sea. The bottom of the sea off the coast of Brazil shoals gradually to between 30 and 40 fathoms, at the distance of between nine and ten leagues from the land." (p. 57).
Ainda sobre o ambiente de formação dos beachrocks, na página 199 da mesma publicação, Darwin faz a seguinte observação: "The shore of the Gulf of Mexico, for a space of many hundred miles, is formed by a chain of lagoons, from one to twenty miles in breadth, [...] containing either fresh or salt water, and separated from the sea by linear strips of sand. Great spaces of the shores of southern Brazil,* and of the United States from Long Island [...] speculates on the origin of these low, sandy, linear islets: he states that the layers of which they are composed are too homogeneous, and contain too large a proportion of shells, to permit the common supposition of their formation being simply due to matter thrown up, where it now lies, by the surf: he considers these islands as upheaved bars or shoals, which were deposited in lines where opposed currents met. It is evident that these islands and spits of sand parallel to the coast, and separated from it by shallow lagoons, have no necessary connection with coral formations [...] * In the London and Edinburgh Philosophical Journal, $1141, p .257$, I have described a singular bar of sandstone lying parallel to the coast off Pernambuco in Brazil, which probably is an analagous formation.".

Embora não citado na publicação de 1842, Darwin descreveu ainda um outro beachrock no Brasil, desta vez no Estado do Rio de Janeiro, em 9 de abril de 1832, conforme consta de sua caderneta de campo (Darwin 1832): "9.th [April 1832] [page 5b] started about 1/2 after six. \& passed over scorching plains cactuses \& other succulent plants (on the decayed \& stunted trees beautiful parasitic Orchis with a deliceous smell) glaring hot: therm: in pocket $96^{\circ}$. - inland brackish lakes with numerous birds. white Egrets - Herons whites \& cormorants. [...] lost our way [...] Geology: found a fragment on beach of sandstone with numerous Mactra. - the whole line of beach is composed of an extensive [page 6b] flat or a lake. between which \& sea are large sand hills. on which the surf roars (by night fine effect) fresh land is gaining. - Sand emits a shrill sound [...] Manatiba dined Temp in shade $84^{\circ}$ our senses were refreshed by food \& a more extended \& prettier view: reflection very clear in the lake."

No Estado do Rio de Janeiro, de norte para sul, foram descritos beachrocks em São Francisco de Itabapoana (Dias \& Silva 1984), Rio das Ostras (Muehe et al. 2007), Ilha do Cabo Frio/Arraial do Cabo (Savi et al. 2005, Castro et al. 2009), restinga de Massambaba (Muehe \& Valentini 1998), Jaconé/Saquarema (Darwin 1832, Francisco 1998, Francisco et al. 1998), Itaipuaçu / Maricá (Muehe \& Ignarra 1984) e Baixada de Jacarepaguá/Rio de Janeiro (Macedo 1971 apud Francisco 1995) e Sepetiba (Francisco \& Góes 1989 apud Francisco 1995). Ocorrências submersas na costa fluminense, em profundidade entre 90-110 m, são conhecidas no litoral de Macaé (Dias et al. 1982) e Cabo Frio (Kowsmann \& Costa 1979 apud Dias et al. 1982). Algumas possuem cimento ferruginoso, como a da região de São Francisco de Itabapoana, e outras apresentam cimentação carbonática, destacando-se o 
beachrock da Ilha do Cabo Frio, que, segundo Savi et al. (2005), possui $92 \%$ de carbonato em sua composição. Já o arenito de Rio das Ostras é cimentado por matéria orgânica (Muehe et al. 2007).

\section{IMPORTÂNCIA DO BEACHROCK DE JACONÉ: CONTEXTO PATRIMONIAL E GEOLÓGICO}

Importância Arqueológica A existência do beachrock na praia de Jaconé, comentada por Darwin em 1832, passou despercebida por mais de 150 anos, uma vez que ele não a publicou. Seixos de beachrock foram também identificados por Lina Kneip nos sambaquis da Beirada e de Moa, em Saquarema (Francisco 1995). Os seixos foram encontrados em camadas arqueológicas datadas entre $4520+/-190$ e $3800+/-190$ anos A.P. no Sambaqui da Beirada e entre $3960+/-190$ e 3610 +/- 190 anos A.P. no Sambaqui de Moa.

Francisco et al. (1998) relatam a ocorrência de beachrock na praia de Jaconé, apresentam sua descrição petrográfica e sedimentológica e sugerem que pelo menos parte dos seixos desta litologia encontrados em dois sambaquis da região seja proveniente do retrabalhamento de fragmentos pelas ondas da praia.

Um Terceiro Olhar sobre o mesmo Afloramento: Projeto Caminhos de Darwin Em 2008 foi iniciado o Projeto Caminhos de Darwin (www.casadaciencia. ufrj.br/caminhosdedarwin). A iniciativa visa resgatar a história da passagem de Charles Darwin pelo Estado do Rio de Janeiro, entre abril e julho de 1832, e estimular atividades relacionadas à sua presença no estado e no país. Faz parte das comemorações dos 150 anos de lançamento da teoria da evolução das espécies pela seleção natural por Charles Darwin e Alfred Wallace, em 2008, e do bicentenário do nascimento de Darwin e da primeira edição do livro Origem das Espécies, em 2009.

$\mathrm{O}$ resgate histórico da passagem de Darwin vem sendo feito pela leitura dos textos dos diários e cadernetas de campo, tradução para o português desse material, pesquisa em material cartográfico dos séculos 18 e 19, disponíveis na Biblioteca Nacional e Arquivo Nacional, além de mapas do século 20, do acervo do DRM-RJ, e visitas aos locais citados nos documentos históricos (Moreira et al. 2009).

A divulgação das informações do projeto é feita pela criação de uma rede de comunicação e ações conjuntas entre os 12 municípios percorridos por Darwin, envolvendo, escolas, moradores, governantes e interessados em geral. Caminha-se rapidamente para a conformação de um roteiro turístico, com forte conteúdo científico, educacional e cultural, nos moldes da categoria dos Itinerários Culturais da UNESCO.

Como parte do levantamento geológico da área, foram identificados os tipos litológicos por ele descritos e, posteriormente, realizadas etapas de campo que, associadas à pesquisa bibliográfica, têm permitido a identificação e localização dos afloramentos. Com isto, foi montado um acervo de rochas, minerais, solos e sedimentos coletados ao longo do trajeto percorrido pelo naturalista britânico e que se transformou em uma coleção que vem sendo exposta nos diversos municípios. Neste contexto, a geologia tem se transformado em um forte elemento integrador de ações de divulgação da história da ciência (Mansur et al. 2009). O beachrock de Jaconé é parte desta coleção e sua beleza estética tem despertado a atenção dos expectadores da exposição.

Decidiu-se por eleger este afloramento (Fig. 1) como sendo o primeiro a ser revisitado na formulação da vertente geológica da proposição dos Caminhos de Darwin como Itinerário Cultural no contexto da História da Ciência, mais de 170 anos após sua passagem e com as tecnologias atuais disponíveis para análise.

Um sítio, para que possa ser classificado como patrimônio no campo da geologia deve, necessariamente, receber uma descrição e seus atributos geológicos relevantes. Sendo assim, além do seu enquadramento num contexto patrimonial, foi realizado um
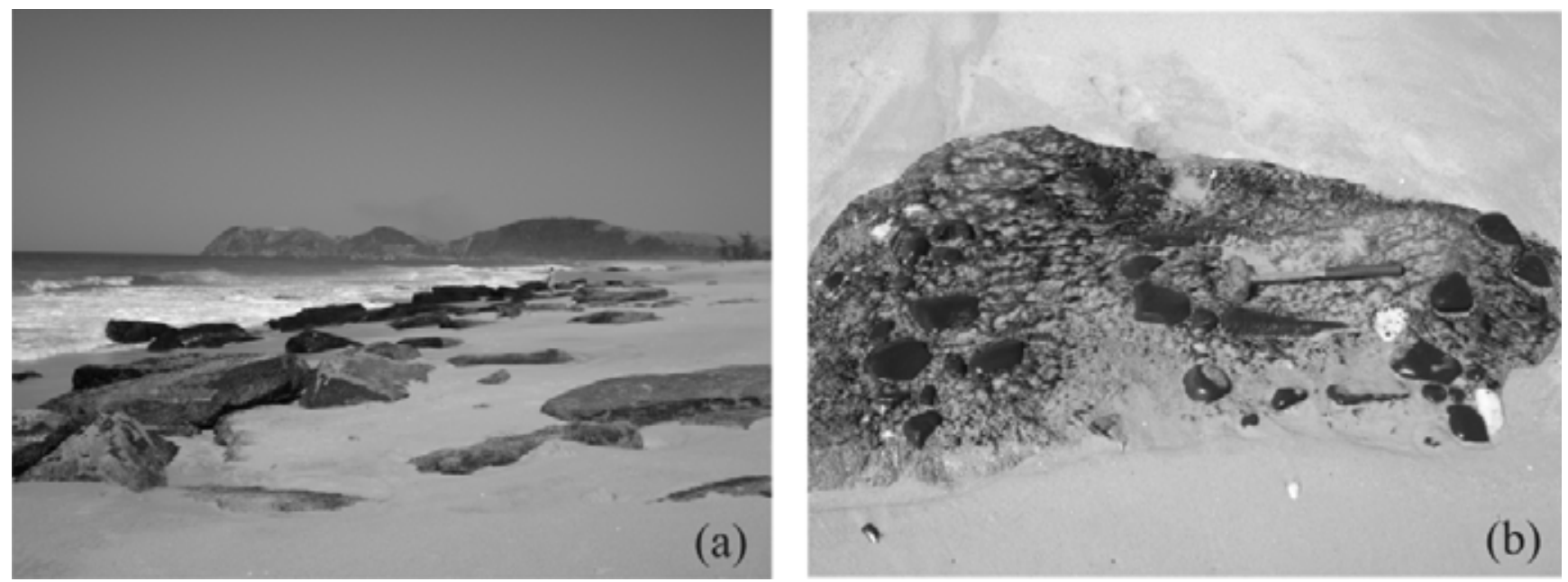

Figura 1 - (a) Afloramentos do beachrock em Jaconé; (b) Conglomerado com seixos e calhaus de diabásio e de quartzo de veio. 
estudo preliminar sobre os aspectos faciológicos, petrográficos e geocronológicos. Buscou-se, desta forma, colher dados para que possa ser melhor apreciado no campo científico e pedagógico, uma vez que, do ponto de vista cultural e turístico, não há dúvidas quanto ao seu valor.

CONTEXTO PATRIMONIAL O conceito de patrimônio associa-se ao sentimento de que os bens culturais, saberes e modos de fazer pertencem a todos e, desta forma, devem ser cuidados para que não se percam. Isto se associa aos diversos tipos de patrimônio, sejam naturais ou construídos, materiais ou imateriais. Segundo Carneiro (2007) são "patrimônio cultural quase todas as coisas que o homem faz ou com as quais se relaciona, desde que a elas se atribua valor que lhes confira essa peculiar condição" (pág. 25). Esta valoração se dá tanto no âmbito dos monumentos construídos quanto dos naturais, sendo uma "única e inseparável realidade [...] são artefato cultural, produto da cultura humana, derivados de um processo de valoração de coisas" (pág. 116). Este sentido de valor é também aplicado ao Patrimônio Geológico.

Como Patrimônio Geológico são classificados os afloramentos únicos, formações geológicas, estilos de deformação etc., de indubitável valor científico e ocorrência restrita. São exemplos didáticos, testemunhos da história geológica, sendo necessária a difusão do conhecimento e a conscientização da sociedade em geral para sua preservação e entendimento da sua importância (Carvajal \& González 2003).

Em geral, classifica-se o Patrimônio Geológico (García-Cortés 1996) por: (a) conteúdo: Estratigráfico, Paleontológico, Tectônico, Hidrogeológico, Petrológico, Geotécnico, Mineiro, Mineralógico, Geomorfológico, Geofísico, Geoquímico e Museus e coleções; (b) utilização: Turística, Científica, Didática e Econômica; (c) influência: Local, Estadual, Nacional e Internacional. Brilha (2005) o define como o conjunto de geossítios de uma dada região, ou seja, locais bem delimitados geograficamente, onde ocorrem um ou mais elementos da geodiversidade com singular valor do ponto de vista científico, pedagógico, cultural, turístico ou outro. Ressalta-se que o sentido de valor, por sua singularidade, foi associado ao conceito.

\section{Patrimônio do tipo História da Ciência A teoria} de Charles Darwin sobre a evolução das espécies pela seleção natural mudou a forma do homem ver o mundo e causou um profundo impacto na humanidade, integrando grandes áreas da ciência.

Em 9 de abril de 1832, no segundo dia de sua expedição ao interior fluminense, Darwin, antes de almoçar em Manatiba ou Mandetiba (Fig. 2), descreve a ocorrência de um arenito na praia. Mandetiba, localizada entre as lagoas de Jaconé e Saquarema, é também local de ocorrência de vários sambaquis, entre eles o de Manitiba, cujo nome parece derivar daquele utilizado nos séculos 18 e 19.
Aos 23 anos, Darwin teve seu primeiro contato com a floresta tropical e isto causou uma forte impressão no jovem naturalista, cuja grande afinidade com a geologia foi consolidada, principalmente, por sua admiração pelo livro Principles of Geology de Charles Lyell (Darwin 1858), então recém-lançado. Darwin descreveu a geologia dos locais por onde passou e deixou sua contribuição aos estudos posteriores, inclusive pela manutenção de um importante acervo de anotações, dados e correspondências, organizados e catalogados. Sua obra completa, incluindo livros, manuscritos, cadernetas e anotações, encontra-se disponível em http:// darwin-online.org.uk.

Recuperar as informações sobre os afloramentos citados ou descritos por Darwin em sua passagem pelo Estado do Rio de Janeiro também resgata parte da história de sua formação como naturalista. A tipologia em que se enquadram estes afloramentos é a da História da Ciência.

Patrimônio pelo Conteúdo Científico e Cultural A importância de afloramentos de beachrock para a identificação de variações do nível relativo do mar no Holoceno é um consenso entre os autores, dadas as suas condições de formação em linhas de praia, apesar de dúvidas lançadas sobre o local apropriado à cimentação no perfil de praia (Kelletat 2006).

O beachrock de Jaconé também pode ser utilizado para entender a ocupação humana pré-histórica, porque seus fragmentos foram coletados pelos sambaquieiros, primeiros habitantes do litoral. O afloramento se classifica como Patrimônio pela possibilidade de utilização científica e cultural por seu conteúdo sedimentar, significado paleoambiental e associação com a arqueologia.

\section{Patrimônio pela Utilização Geoturística e Didática} Na região da Costa do Sol do estado do Rio de Janeiro, onde se localizam Maricá e Saquarema, o dito "Turismo de Sol e Praia" é muito desenvolvido. Localmente, as características das ondas de algumas praias, como a de Itaúna, fazem com que a cidade seja sede de campeonatos de surfe, inclusive internacionais, o que amplia ainda mais o recebimento de visitantes. No entanto, a qualidade da visitação turística pode ser melhorada pela inserção de informações científicas e culturais. Em Saquarema já foram implantados painéis do Projeto Caminhos Geológicos e Caminhos de Darwin e, ainda, pode-se visitar o Sambaqui da Beirada, espaço musealizado, onde os achados arqueológicos estão expostos in situ (Fig. 3).

A discussão em curso para transformação em Itinerário Cultural do trajeto da excursão de Darwin pelo interior fluminense, sob a perspectiva da História da Ciência, baseia-se na possibilidade de agregar o caráter científico ao do patrimônio cultural já existente, uma vez que vários dos locais por onde ele passou ainda estão preservados e são tombados por atos municipais, estaduais ou federais. Isto encontra suporte no texto da Carta dos Itinerários Culturais (http://icomos.fa.utl.pt/ 


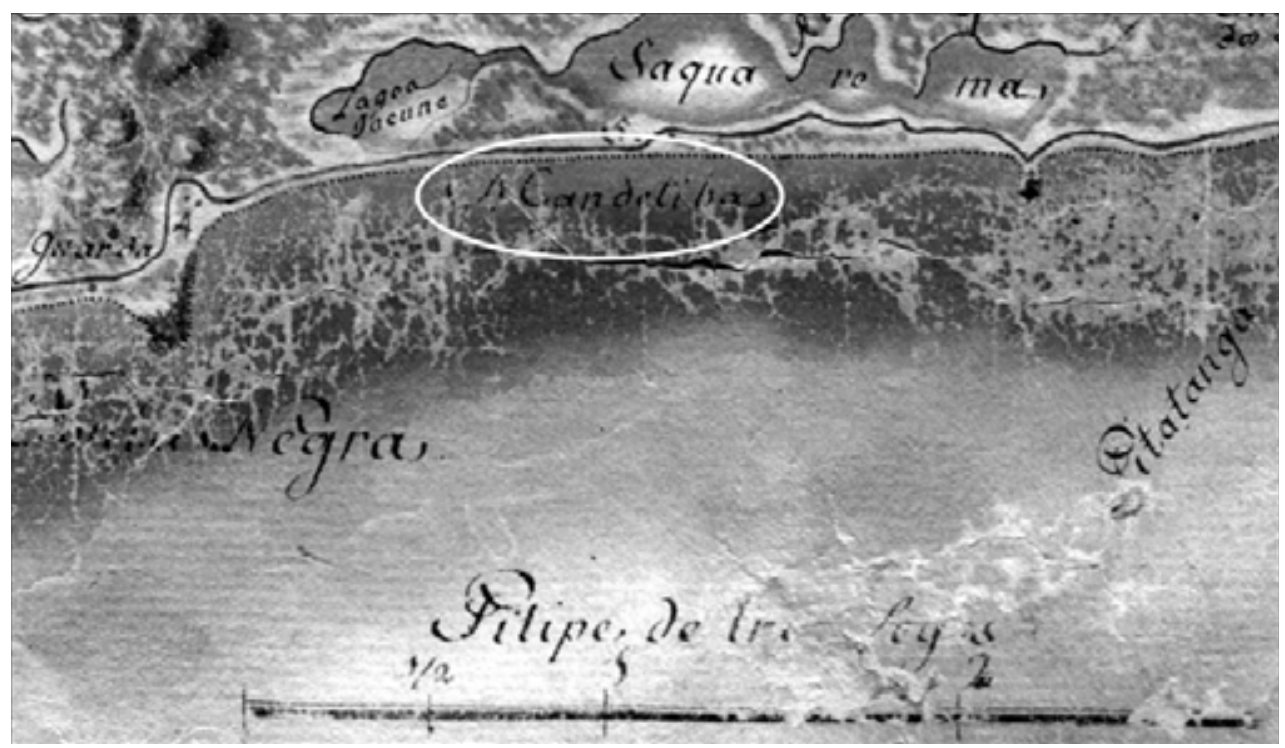

Figura 2 - Localização de Mandetiba, entre Jaconé e Saquarema. Fonte: Cartas Topográficas da Capitania do Rio de Janeiro mandadas tirar pelo $M^{m o}$. Ex $x^{m}$. Sr. Conde da Cunha Capitam General e Vice Rey do Estado do Brazil no anno de 1767. Acervo da Biblioteca Nacional (arquivo cart512339fo7).
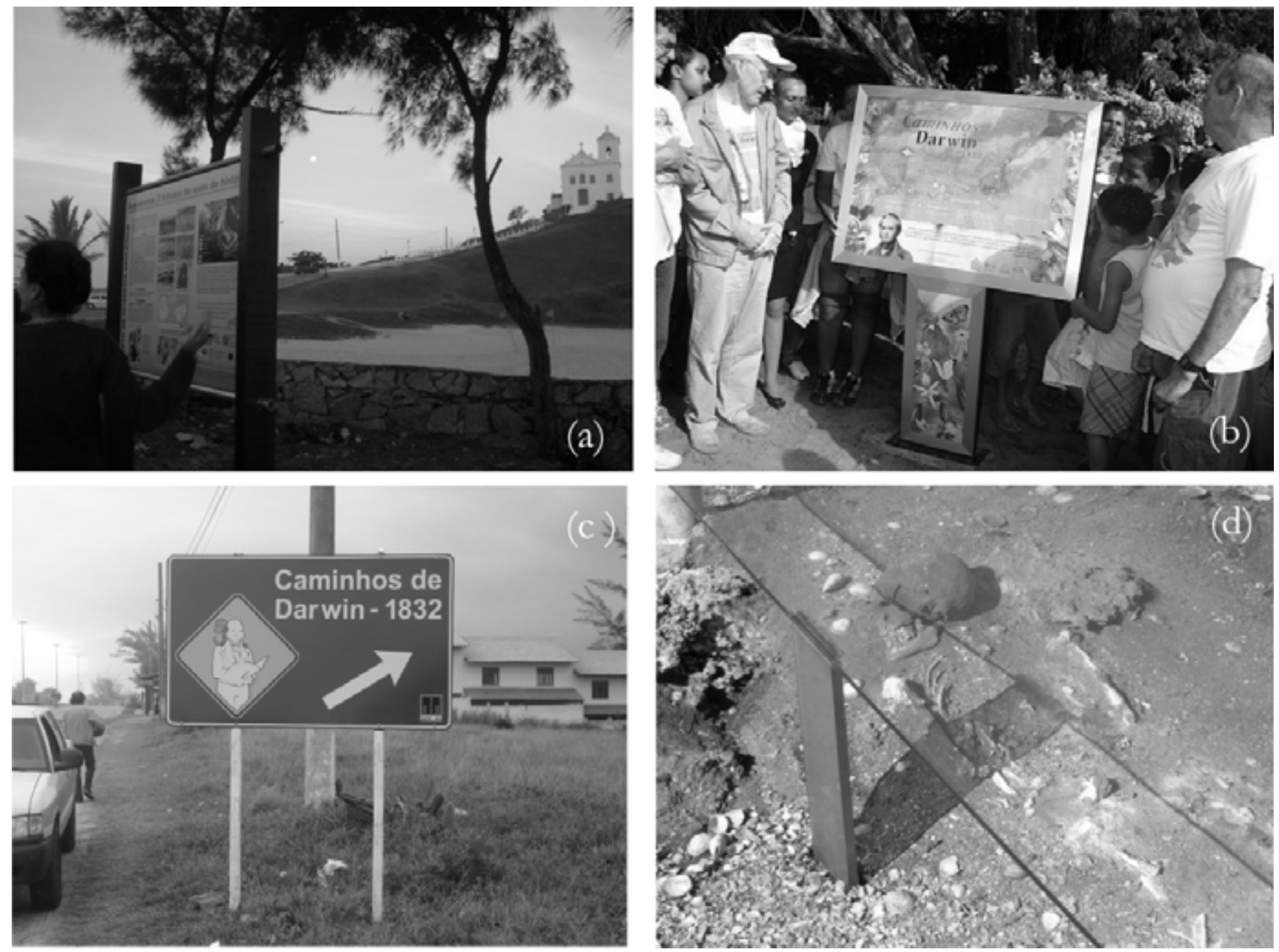

Figura 3 - (a) Painel interpretativo do projeto Caminhos Geológicos próximo à igreja de Nossa Senhora de Nazaré (Saquarema), patrimônio histórico, cujo prédio atual foi erguido no século 19; (b) marco da passagem de Darwin em Manitiba, implantado pelo projeto Caminhos de Darwin; (c) placa de sinalização do projeto Caminhos de Darwin na Praia de Jaconé; e (d) Sambaqui da Beirada (Saquarema). 
documentos/documentos.html). Assim como nos casos da Estrada Real ou do Caminho de Santiago de Compostela, é possível estabelecer para os Caminhos de Darwin uma conexão entre os locais por onde ele passou e a ciência, permitindo que a história seja entrelaçada e o turismo científico possa se juntar ao histórico-cultural e, mesmo, o de "Sol e Praia".

Do ponto de vista didático, o afloramento do beachrock de Jaconé é de alta relevância porque expõe distintas fácies sedimentares, de rara observação em um território dominado por rochas metamórficas e ígneas.

Patrimônio com Influência Internacional As descrições geológicas efetuadas por Charles Darwin no Estado do Rio de Janeiro, e nas demais localidades por onde passou, se configuram como Patrimônio de Influência Internacional (García-Cortés 1996), uma vez que é parte indissociável de sua obra e contribuíram para sua formação científica e elaboração teórica. Não são patrimônios de estados ou países, são patrimônios da ciência com relevância mundial.

\section{CONTEXTO GEOLÓGICO}

A Praia A praia de Jaconé, onde ocorrem afloramentos de beachrock (Fig. 4), apoia-se em dois promontórios, o de Saquarema a leste e o de Ponta Negra a oeste. Ao norte da faixa de beachrocks, encontra-se a lagoa de Jaconé e sua planície parcialmente colmatada e brejosa, separadas da praia por típico cordão arenoso. A rede de drenagem da serra de Jaconé alimenta a lagoa de Jaconé e as áreas brejosas adjacentes.

Do ponto de vista da morfodinâmica, a praia de Jaconé pode ser classificada como do tipo refletiva (Wright \& Short 1984 apud U.S. Army Corps of Engineers 1995). Análise granulométrica de amostra da face de praia (Fig. 5), coletada em ambiente semelhante àquele interpretado como sendo o dos beachrocks, mostrou predominância de sedimentos na faixa de areia grossa a média (phi médio $=-0,3317$ ), grãos bem selecionados $($ seleção $=0,4895)$, configurando-se como ambiente de alta energia. Não foram observados seixos e calhaus, exceto aqueles originados pelo retrabalhamento do próprio beachrock, que em geral são discoides (oblatos), mostrando a abrasão sofrida no embate com as ondas.

Do ponto de vista composicional, observou-se predominância de quartzo e valvas de moluscos. O teor em bioclastos, que chega a alcançar cerca de $80 \%$ dos constituintes na fração maior de areia muito grossa, vai diminuindo de percentual, até praticamente desaparecer na fração areia muito fina. $\mathrm{O}$ quartzo apresenta-se como grãos bem arredondados, em geral prolatos, quanto maior a granulometria. Na fração areia fina, os grãos apresentam-se angulosos a subangulosos. Inclusões são frequentes (Figs. 6a e 6b).

Fragmentos angulosos a bem arredondados do próprio beachrock são observados desde as frações

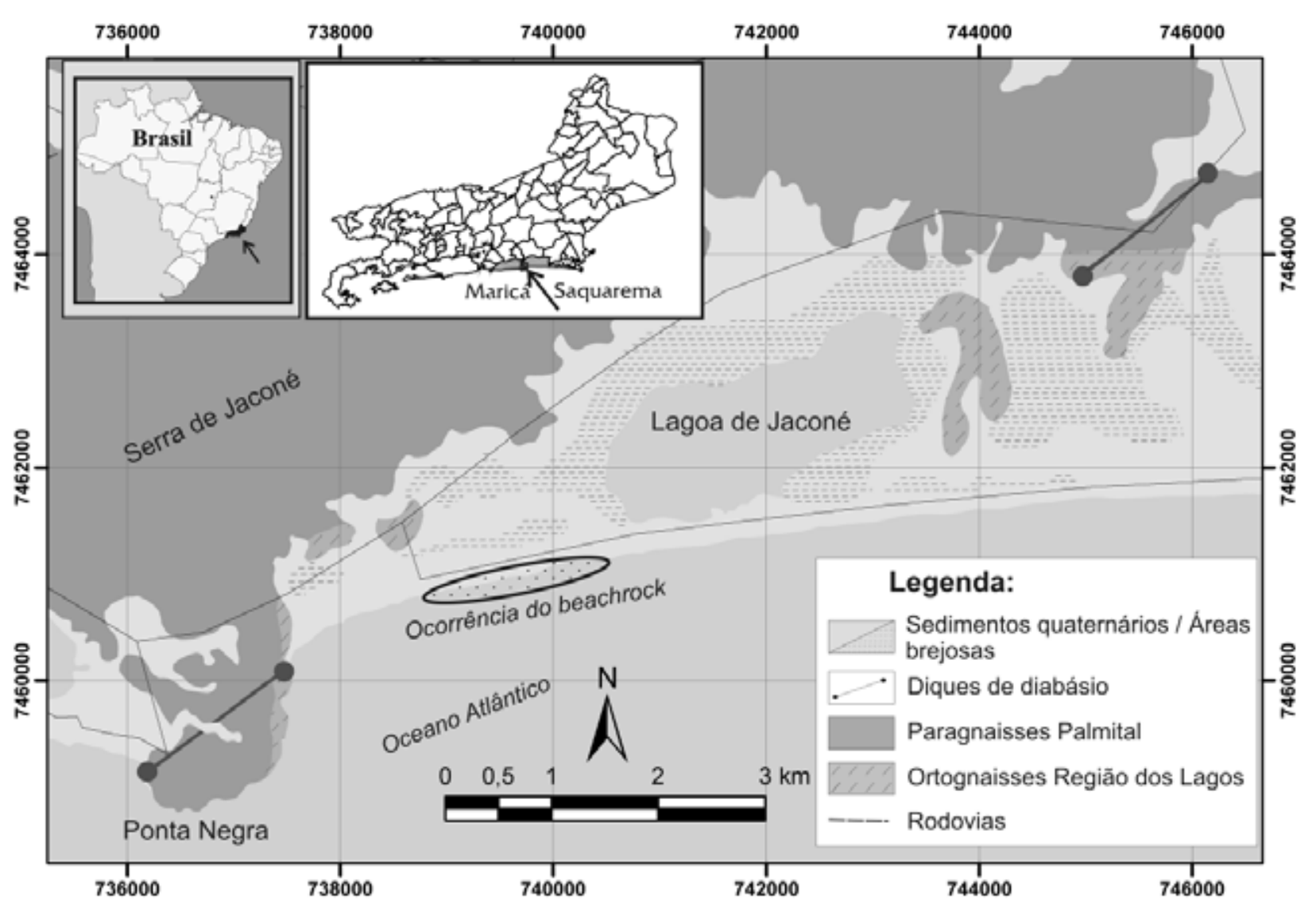

Figura 4 - Mapa geológico da região de ocorrência do beachrock em Saquarema. (modificado de DRM 1981). 
Beachrock de Jaconé, Maricá e Saquarema - RJ: importância para a história da ciência e para o conhecimento geológico

Histograma x Frequência Acumulada

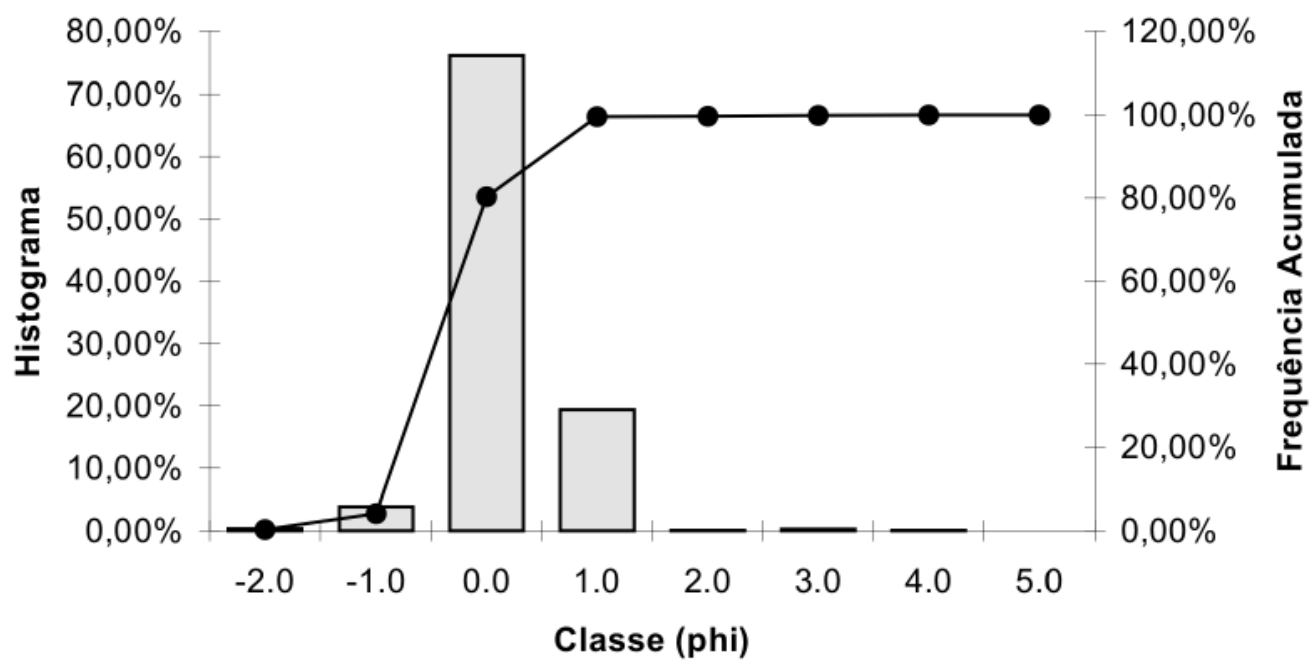

Figura 5 - Gráfico relativo à análise granulométrica de areia da praia de Jaconé, coletada nas proximidades dos beachrocks.
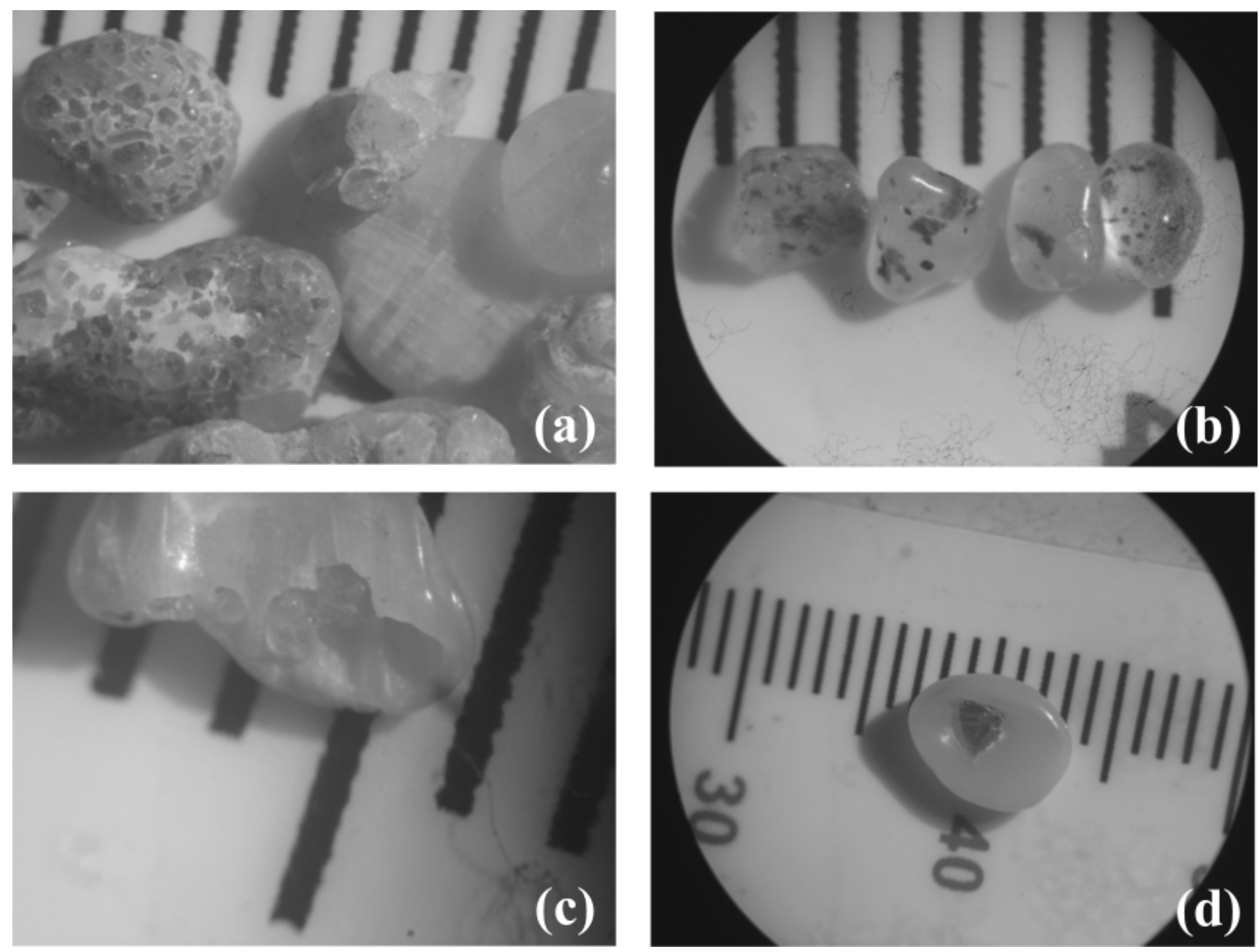

Figura 6 - Aspectos da areia da praia atual: (a) grãos arredondados de beachrock e de quartzo; (b) grãos de quartzo com inclusões de turmalina e opacos; (c) bioclasto aprisionando grãos de quartzo; e (d) grão de quartzo cimentado sobre bioclasto. Escala: menor divisão $=1 \mathrm{~mm}$. 
mais grossas até areia média. Trata-se de clastos finos de beachrock, de tonalidades amareladas a amarronzadas (Fig. 6a). Foi observada, ainda, cimentação incipiente entre grãos de quartzo localizado sobre e dentro de fragmentos de valvas (Figs 6c e 6d). Biotita, espinhos de equinoides e pequenos fragmentos de turmalina e ilmenita foram também encontrados na fração areia fina.

Descrição litofaciológica do beachrock A faixa de ocorrência dos beachrocks estende-se aproximadamente por $1100 \mathrm{~m}$, aflorando por cerca de $700 \mathrm{~m}$. As melhores possibilidades de visitação ocorrem nos períodos de marés baixas. Foram identificadas 3 litofácies nos afloramentos e em matacões do beachrock:

\section{LITOFÁCIES 1 (ARENITOS COM ESTRATIFICA-} ÇÃO CRUZADA DE BAIXO ÂNGULO) A litofácies mais frequente é representada por arenitos com estratificação cruzada de baixo ângulo (swash cross stratification), marcada pela alternância de lâminas e de camadas centimétricas de areia grossa a muito grossa e de areia média (Fig. 7a), com abundantes valvas de biválvios fragmentadas e grânulos e seixos de quartzo arredondados a subarredondados. Medidas da atitude da estratificação em alguns poucos afloramentos indicaram ângulos em torno de $12-13^{\circ}$ em direção ao mar. Segundo Russel \& McIntire (1965), o ângulo de mergulho dos sets é controlado pelo tamanho dos grãos e, quanto maior a granulometria dos sedimentos, maior a inclinação dos planos de estratificação, bem como da face de praia. Em praias de areia fina a média, o mergulho da face praial varia de 2 a $10^{\circ}$ (McCubbin 1982). A praia atual, composta predominantemente por areia grossa, apresenta mergulho da face de praia em direção ao mar entre 10 e $15^{\circ}$, o que reforça a atitude obtida no arenito de praia. O mergulho da estratificação em direção ao mar, bem como a boa seleção dos sedimentos, o elevado arredondamento das partículas e a predominância da fração areia grossa, sugerem deposição na face de praia (foreshore), onde dominam processos trativos de alta energia. Esta litofácies é formada por
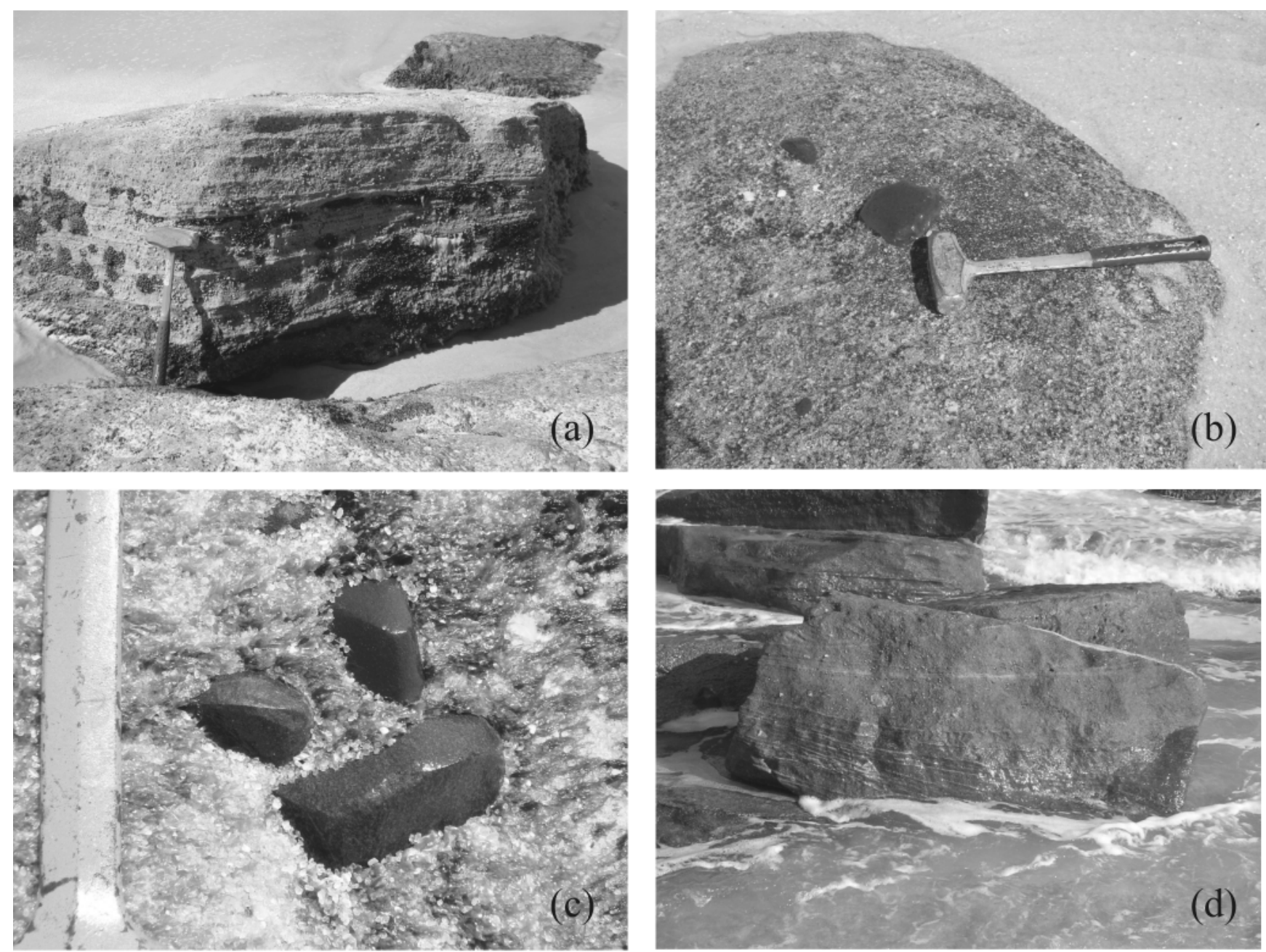

Figura 7 - Litofácies. (a) Arenito grosso a muito grosso com estratificação cruzada de baixo ângulo (marreta $=40 \mathrm{~cm}$ ). (b) Conglomerado fino com seixos de diabásio e de quartzo leitoso, e abundantes valvas de biválvios. (c) Seixos de diabásio facetados pela ação abrasiva da areia sobre o beachrock (largura da haste da marreta $=2 \mathrm{~cm}$ ). (d) Bloco de conglomerado quartzoso mostrando geometria acanalada (altura do matacão aproximadamente $80 \mathrm{~cm}$ ). 
processo de espraiamento das ondas, que se processa em ângulos diferentes, gerando cúspides e depressões na antepraia e, consequentemente, sets cruzados limitados por superfícies de truncamento de baixo ângulo. $\mathrm{O}$ espraiamento da onda e o refluxo produzem o característico selecionamento dos sedimentos em lâminas e camadas individuais (Clifton 1969). Autores como Oliveira et al. (1990), Assis et al. (1990) e Vieira et al. (2007), estudando os beachrocks do Nordeste do Brasil, também interpretaram esta litofácies como indicativa de deposição nesta zona. Os últimos autores sugerem que a presença de areias grossas bem selecionadas com baixo conteúdo de seixos, característica textural dessa litofácies no beachrock de Jaconé, está relacionada à deposição na parte superior da face de praia (upper foreshore).

LITOFÁCIES 2 (CONGLOMERADOS QUARTZOSOS E COQUINAS COM ESTRATIFICAÇÃO MAL DEFINIDA) Outra litofácies notável em Jaconé é representada por conglomerados quartzosos finos com fragmentos de valvas ou coquinas, com abundantes grânulos de quartzo bem arredondados, moderadamente selecionados, com elevado conteúdo de areia grossa a muito grossa, contendo seixos e calhaus bem arredondados de diabásio e, mais escassamente, de quartzo de veio (Fig. 7b). Os seixos e calhaus possuem diâmetros de 1 a $25 \mathrm{~cm}$ e ocorrem em camadas de conglomerado fino com até $50 \mathrm{~cm}$ de espessura, com estratificação mal definida, indicada pela orientação das valvas fragmentadas e dos seixos alongados. Esta litofácies pode ser interpretada como depósito residual formado na parte inferior da face de praia durante eventos de tempestade ("ressacas"), onde, devido ao ataque frontal por ondas, houve remoção e transporte das partículas finas para águas mais fundas (Vieira et al. 2007). Um aspecto interessante dos afloramentos desta litofácies é a superfície facetada dos seixos e calhaus de diabásio, produzida pela ação abrasiva dos grãos de areia durante o espraiamento e refluxo das ondas (Fig. 7c).

LITOFÁCIES 3 (ARENITOS CONGLOMERÁTICOS E CONGLOMERADOS FINOS COM GEOMETRIA ACANALADA) Uma terceira litofácies, escassamente observada, é caracterizada por arenitos conglomeráticos e conglomerados finos com grânulos e seixos de quartzo e fragmentos de valvas, em camadas lenticulares com espessura variando de 2 a $20 \mathrm{~cm}$, separadas por lâminas e camadas delgadas de arenito fino a médio com laminação plano-paralela, mostrando geometria acanalada (Fig. 7d). Esta litofácies pode ser atribuída a ondas de tempestade produzindo, na parte superior da zona de surf (upper shoreface), megaondulações em sedimentos grossos, com posterior decantação de areia fina após o evento. Outra possibilidade seria a atuação de correntes de deriva litorânea produzindo a migração de formas de leito de crista sinuosa. Supõe-se que a maior parte dos afloramentos desta litofácies esteja na zona de arrebentação atual, inacessível durante os trabalhos de campo.
Petrografia Foram elaboradas 5 lâminas delgadas das duas principais litofácies registradas no beachrock de Jaconé, quais sejam, a Litofácies 1 (4 lâminas: JAC 1, JAC 2, JAC 3 e JAC 4) e a Litofácies 2 (1 lâmina: JAC 5). Foram observados os aspectos texturais e composicionais das rochas sedimentares, bem como os processos diagenéticos que ocorreram durante a litificação. Cabe ressaltar que as lâminas não foram impregnadas e que foram contados 300 pontos para definir a composição mineralógica.

LITOFÁCIES 1 Constituem arenitos finos a muito grossos com grânulos, compostos predominantemente por grãos de quartzo subangulosos a arredondados, com seleção moderada a boa (Fig. 8a), contendo quantidade subordinada de bioclastos, feldspatos e de fragmentos líticos. Na fração quartzosa, predominam amplamente os grãos monocristalinos, com escassa quantidade de quartzo policristalino com 2 ou 3 subgrãos. Ocorrem em maior quantidade os grãos com extinção reta e, subordinadamente, com extinção suave ondulante, sendo raro o quartzo com extinção ondulante forte. São comuns quartzos com inclusões sólidas de zircão, biotita e turmalina, e escassos aqueles com inclusões fluidas alinhadas. A fração quartzosa fina a média apresenta grãos subarredondados a subangulosos, sendo que os grãos grossos/muito grossos e grânulos são normalmente arredondados a muito bem arredondados. O quartzo nesta litofácies apresenta percentagens entre 55 e $57 \%$ e, extraindo-se da contagem o cimento e a porosidade, a quantidade varia de 80 a $94 \%$ (Tabs. 1 e 2).

Entre os feldspatos, predominam grãos subangulosos de microclina, normalmente sem alteração, ocorrendo subordinadamente clastos de ortoclásio e, raramente, de plagioclásio. Em algumas lâminas foi observada a substituição do feldspato por calcita. Os fragmentos líticos são bastante escassos, normalmente tamanho grânulo, predominando os de origem plutônica (pegmatitos), compostos por microclina e quartzo. A quantidade de bioclastos no arcabouço varia de 1 a $17 \%$, sendo normalmente constituídos por fragmentos de valvas de biválvios com as bordas muito arredondadas, fortemente orientadas e constituindo a maior parte da fração mais grossa dos arenitos. Entre os minerais acessórios, foram observados grãos pequenos de biotita (às vezes cloritizada), turmalina (chorlita), piroxênio, anfibólio, zircão, além de muscovita e opacos.

$\mathrm{O}$ tipo de cimento carbonático mais comum nos arenitos desta litofácies é representado pelas franjas isópacas prismáticas (isopachous prismatic rims), compostas por pequenos cristais prismáticos dispostos perpendiculares à superfície dos grãos siliciclásticos e bioclásticos (Fig. 8b). Observou-se nas lâminas diferenças no que se refere à quantidade deste tipo de cimento (Tab. 1), que varia entre cerca de 14 e $32 \%$ do volume total das rochas. Na lâmina JAC 4 observa-se apenas uma franja estreita, pouco desenvolvida, que confere a essa amostra o maior volume de poros entre todas as observadas. Nas lâminas JAC 2 e JAC 3, as franjas isópacas são mais espessas, muitas vezes preenchendo 


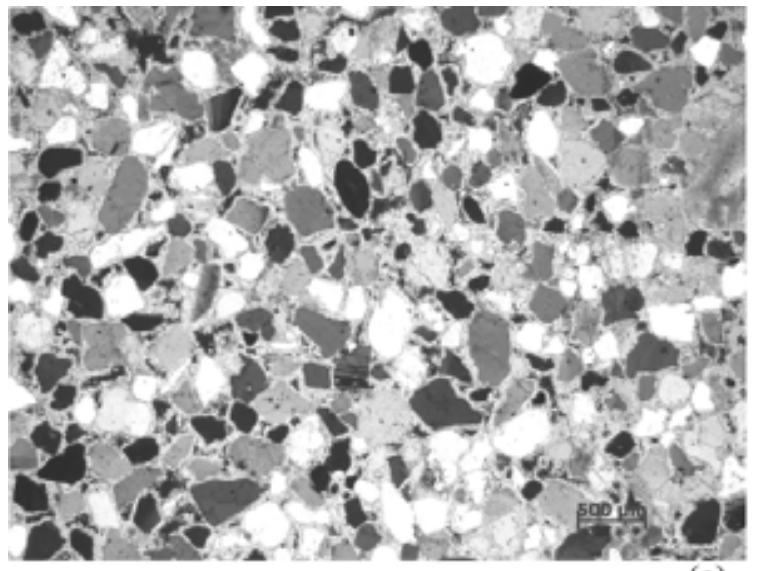

(a)

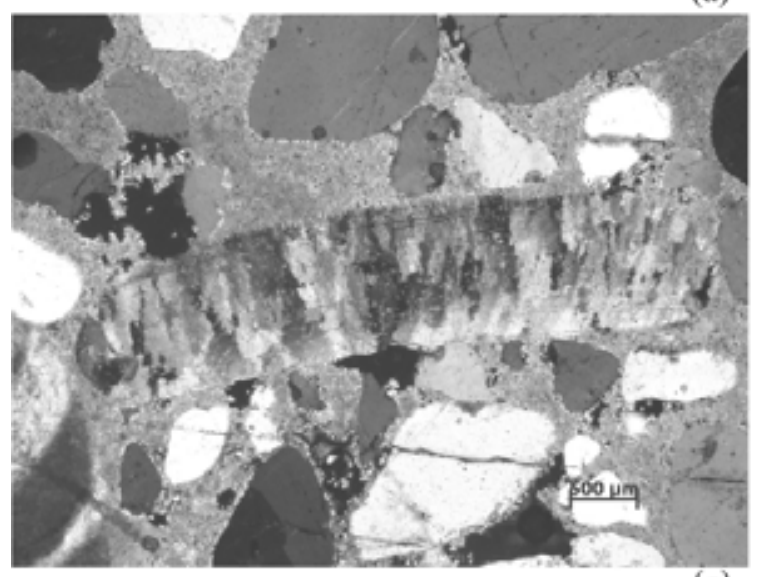

(c)

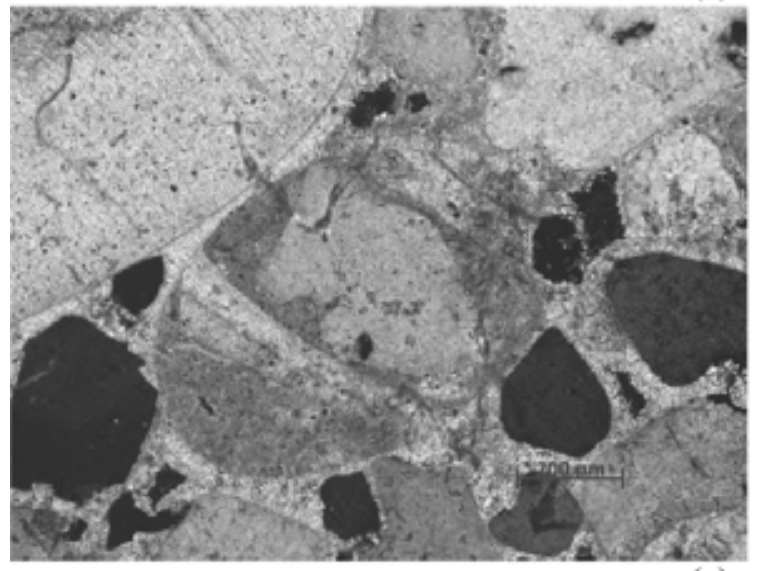

(e)

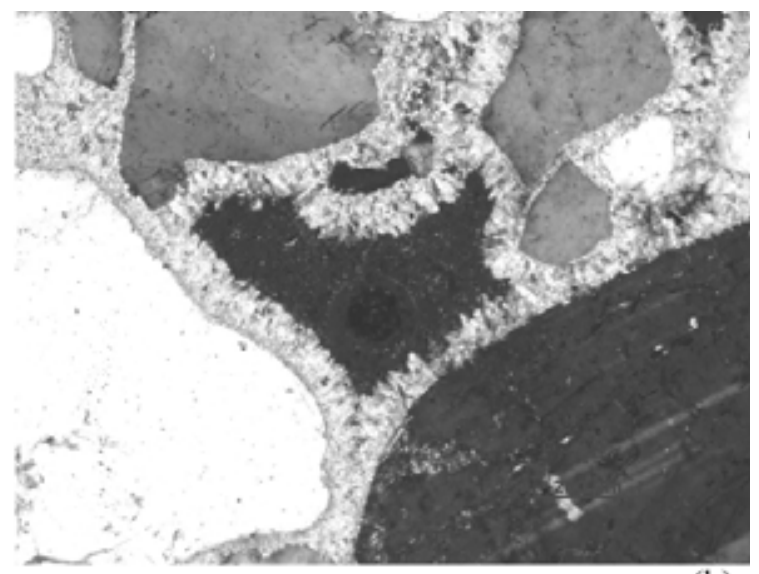

(b)

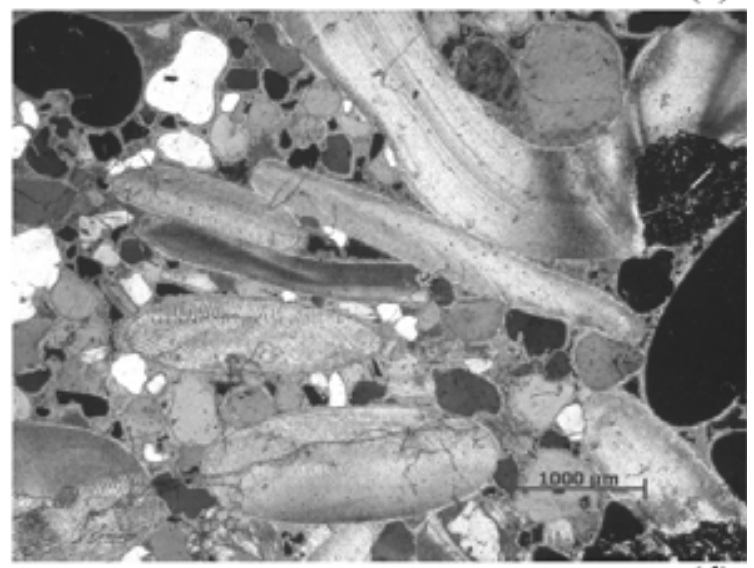

(d)

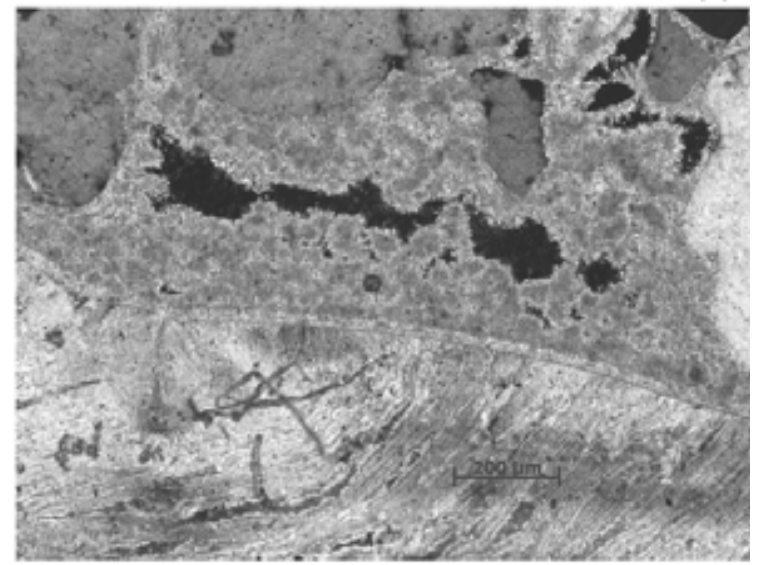

(f)

Figura 8 - Petrografia (a) JAC 2, polarizador cruzado: arenito médio quartzoso, bem selecionado, com grãos de quartzo monocristalino subangulosos a subarredondados; (b) JAC 3, polarizador cruzado: cimento do tipo franja isópaca prismática; (c) JAC 1, polarizador cruzado: cimento do tipo equant spar preenchendo a porosidade intergranular; ao centro, bioclasto recristalizado; (d) JAC 5, polarizador cruzado: bioclastos tamanho grânulo e seixo fino bem arredondados em arenito da Litofácies 2; (e) JAC 5, polarizador cruzado: grão arredondado de antigo beachrock; (f) JAC 5 , polarizador cruzado: poro parcialmente preenchido por cimento do tipo agregado pseudopeloidal.

completamente a porosidade intergranular. Nestas amostras, a porosidade apresenta volumes semelhantes, variando entre 6 e $8 \%$, conforme observado na tabela 1 . Segundo Longman (1980), as franjas isópacas indicam a precipitação de carbonato de cálcio em zona freática marinha ativa, onde a água salgada percolou pelo sedimento através das marés, ondas ou correntes.
A presença de uma finíssima franja de cristais muito pequenos no contato com os clastos, nos beachroks do Rio Grande do Norte, foi interpretada por Vieira \& De Ros (2006) como produto de elevada concentração de carbonato durante os estágios iniciais de precipitação rápida. Com o subsequente decréscimo na concentração de carbonato, a precipitação desacelerou 
Tabela 1 - Percentagem de grãos do arcabouço, cimento e porosidade dos beachrocks de Jaconé.

\begin{tabular}{|c|c|c|c|c|c|c|c|c|c|c|c|}
\hline & Lif & $\mathrm{Qz}$ & $\mathrm{F}$ & Lit & Bioc & $\mathrm{Bi}$ & $\mathrm{Tu}$ & Py/Anf & $\mathrm{Zi}$ & $\mathrm{Cim}$ & Poros \\
\hline JAC 1 & 1 & 57 & 1,4 & 0,3 & 12 & & & 0,3 & & 29 & \\
\hline JAC 2 & 1 & 57 & 2,3 & & 1 & & & & 0,3 & 31,7 & 7,7 \\
\hline JAC 3 & 1 & 55,7 & 3,7 & & 5 & 0,3 & 0,3 & & & 28,7 & 6,3 \\
\hline JAC 4 & 1 & 55,7 & 4,3 & 0,3 & 4,7 & & & & & 13,7 & 21,3 \\
\hline JAC 5 & 2 & 48,4 & 0,3 & 3,7 & 25 & & & 0,3 & & 20 & 2,3 \\
\hline
\end{tabular}

Lif - litofácies; Qz - Quartzo; F - Feldspato; Lit - Líticos; Bioc - Bioclastos; Bi - Biotita; Tu - Turmalina; Py - Piroxênio; Anf - Anfibólio; Zi - Zircão; Cim - Cimento.

Tabela 2 - Percentagem de grãos do arcabouço dos beachrocks de Jaconé.

\begin{tabular}{|c|c|c|c|c|c|c|c|c|c|}
\hline & Lif & $\mathrm{Qz}$ & $\mathrm{F}$ & Lit & Bioc & $\mathrm{Bi}$ & $\mathrm{Tu}$ & Py/Anf & $\mathrm{Zi}$ \\
\hline JAC 1 & 1 & 80,2 & 1,9 & 0,5 & 16,9 & & & 0,5 & \\
\hline JAC 2 & 1 & 94 & 3,8 & & 1,7 & & & & 0,5 \\
\hline JAC 3 & 1 & 85,7 & 5,6 & & 7,7 & 0,5 & 0,5 & & \\
\hline JAC 4 & 1 & 85,7 & 6,6 & 0,5 & 7,2 & & & & \\
\hline JAC 5 & 2 & 62,3 & 0,4 & 4,7 & 32,2 & & & 0,4 & \\
\hline
\end{tabular}

formando cristais maiores e prismáticos, que puderam crescer até obliterar a porosidade.

Já a amostra JAC 1 apresenta cimento caracterizado por cristais aproximadamente equantes, com diâmetros médios entre 15 e $30 \mu \mathrm{m}$, que preenchem quase que completamente o espaço intergranular, proporcionando porosidade desprezível (Fig. 8c). Este tipo de cimento assemelha-se ao descrito por Vieira \& De Ros (2006) nos beachrocks potiguares, denominado de equant spar. Segundo Longman (1980), este cimento indica precipitação em ambiente predominantemente marinho raso.

LITOFÁCIES 2 A única lâmina desta litofácies mostra um conglomerado fino com a fração grossa representada por grânulos de quartzo arredondados e bioclastos, moderadamente selecionado (Fig. 8d), em cujo afloramento foram observados seixos de diabásio e de quartzo leitoso (Figs. 7b e 7c). Conforme as tabelas 1 e 2, predomina o quartzo, com amplo domínio dos grãos monocristalinos sobre os policristalinos, e da extinção reta sobre a suave ondulante. A fração areia grossa/muito grossa e grânulo apresentam clastos arredondados a muito bem arredondados, e a fração areia fina/média, clastos arredondados a subangulosos. Nesta litofácies, a despeito do quartzo ainda predominar, ele apresenta percentagem menor do que na Litofácies 1 devido a uma maior quantidade de bioclastos na rocha (25\% do arcabouço). Os bioclastos, como na Litofácies 1 , são formados quase que exclusivamente por fragmentos de biválvios, tamanho grânulo até seixo fino (4 a $8 \mathrm{~mm}$ sensu Blair \& McPherson 1999). O feldspato é escasso, formado principalmente por microclina, tendo sido observados poucos grãos de plagioclásio e ortoclásio. Em relação aos líticos, apresenta quantidade bastante superior à da Litofácies 1, sendo representados por grânulos e seixos finos de fragmentos de rocha pegmatítica ácida, compostos por microclina e quartzo com extinção suave ondulante. Cabe ressaltar que não foram observados clastos de diabásio. Foram ainda descritos grãos de zircão, hiperstênio, biotita e opacos. Foi observado um clasto tamanho areia grossa, possivelmente oriundo de um beachrock mais antigo, composto por um grão de quartzo e fragmentos bioclásticos, cimentados por carbonato micrítico (Fig. 8e).

O processo de cimentação foi mais complexo que na Litofácies 1 . O cimento constitui $20 \%$ do volume total da rocha e a porosidade intergranular é bastante reduzida (Tab. 1). Os clastos são envolvidos por uma franja contínua com espessura de $25 \mu \mathrm{m}$, podendo alcançar $35 \mu \mathrm{m}$, composta por pequenos cristais prismáticos perpendiculares à superfície dos grãos e, tal qual na litofácies anterior, uma finíssima (4 a $6 \mu \mathrm{m})$ franja de carbonato microcristalino entre esta e a superfície dos grãos. Preenchendo o espaço intergranular, predomina cimento carbonático criptocristalino (micrítico) de coloração castanha, formando agregados pseudopeloidais (pseudo-peloidal aggregates) com formas subesféricas a elípticas (Fig. 8f), diâmetros entre 15 e $35 \mu \mathrm{m}$, e recobertas por franjas descontínuas de pequenos cristais prismáticos, tal qual registrado por Vieira \& De Ros (2006). Também ocorrem poros preenchidos por cimento micrítico maciço. A franja que envolve os clastos pode ser classificada da mesma forma que na Litofácies 1, como formada na zona freática marinha ativa. A origem do cimento pseudopeloidal, segundo os autores acima, 
deve-se a repetidas nucleações de calcita submicrocristalina ao redor de centros de crescimento, por processos exclusivamente físico-químicos ou com participação biológica. A presença de pequenos cristais prismáticos ao redor dos agregados pode indicar evaporação de água salgada retida nos poros em condições subaéreas.

DATAÇÃO PELO MÉTODO DO ${ }^{14} \mathrm{C}$ Uma amostra do beachrock da Litofácies 2 foi selecionada para datação pelo método do radiocarbono, dada a presença abundante de conchas de biválvios (Hughen et al. 2004). A amostra foi inicialmente tratada duas vezes com uma solução de $0,5 \mathrm{~mol} \mathrm{l}^{-1} \mathrm{HCl}$, de modo a retirar os depósitos superficiais de carbonato. Após a lavagem com água deionisada, foi desintegrada manualmente, procurando-se retirar os fragmentos de concha existentes. Depois, a amostra foi peneirada em malha de $1 \mathrm{~mm}$, tornando-se a coletar eventuais fragmentos de concha remanescentes. Duas frações foram encaminhadas para datação no Centro de Estudos Isotópicos Aplicados (CAIS), Universidade da Geórgia (Athens, USA): (a) o material fino peneirado, contendo areia fina e cimento carbonático; e (b) os fragmentos de concha.

A concentração de ${ }^{14} \mathrm{C}$ nas amostras foi determinada pela técnica AMS e as idades radiocarbônicas obtidas foram calibradas empregando-se o programa Radiocarbon Calibration Program (CALIB) versão 5.02 (2005) (Stuiver \& Reimer 1993). Os resultados obtidos mostraram que os fragmentos de valvas do beachrock têm idade de 8198-7827 cal BP e o cimento de 6008-5786 cal BP.

\section{INTERPRETAÇ̃̃O DOS RESULTADOS E CON-} CLUSÕES Trabalho de campo na região que vai do sopé da serra de Jaconé até a região de ocorrência dos beachrocks mostrou a existência de pelo menos 3 afloramentos de corpos pegmatíticos com dimensões métricas e vários grandes blocos rolados de quartzo, além da presença de clastos rolados nos pequenos rios que descem da serra. Esta, portanto, pode ser a origem de parte dos seixos e calhaus de quartzo encontrados no conglomerado. Entretanto, nenhum afloramento ou clastos de diabásio foi encontrado, apesar dos seixos e calhaus desta litologia predominarem sobre os de quartzo nos beachrocks conglomeráticos.

No entanto, na região ocorrem dois afloramentos de diques básicos (Fig. 4), um na Ponta Negra e outro próximo à Lagoa de Jaconé, separados por uma área de cobertura holocênica, e que, se unidos por uma linha, podem ser interpretados como um único corpo subjacente à área de ocorrência dos beachrocks. Antes da deposição dos sedimentos que vieram a formar o beachrock, há cerca de 8000 anos A.P., o nível relativo do mar esteve bem abaixo do atual, resultando uma paisagem bem distinta. Naquela época, a planície adjacente à praia atual ainda não estava colmatada por sedimentos, e era provavelmente dissecada pelo baixo curso das drenagens que desciam da serra. Constituía uma área de relevo formado por colinas baixas, onde afloravam rochas do embasamento cristalino e o grande dique de diabásio.
O corpo ígneo exposto sofria intemperismo químico do tipo esfoliação esferoidal, produzindo uma grande quantidade de seixos e calhaus arredondados, que eram removidos pela ação fluvial e/ou pela ação marinha durante a transgressão iniciada há cerca de 12000 anos A.P. Assim, durante a deposição dos sedimentos que formaram o beachrock, teria havido uma grande disponibilidade de clastos de diabásio ao longo de toda $\mathrm{a}$ área atravessada pelo dique, que foram retrabalhados $\mathrm{e}$ depositados pela ação das ondas. Em relação aos clastos de quartzo leitoso presentes no beachrock, uma parte significativa destes pode ter sido originada de modo semelhante aos clastos de diabásio, ou seja, através do intemperismo do embasamento cristalino adjacente então exposto, e de sua erosão e retrabalhamento por processos fluviais e/ou marinhos.

O beachrock de Jaconé, parcialmente aflorante numa extensão de $700 \mathrm{~m}$ de praia, e submerso ao longo de extenso trecho, tanto para leste como para oeste, indica um paleonível do mar provavelmente um pouco mais baixo que o atual. As idades obtidas qualificam a ocorrência como um dos mais velhos beachrocks datados no Estado do Rio de Janeiro e mostra a necessidade de ampliar os estudos ora iniciados.

Observou-se que os sedimentos da praia atual diferem dos registrados no beachrock, principalmente no que se refere à ausência de seixos e calhaus, bem como a escassez relativa de fragmentos de biválvios. A Litofácies 1 do beachrock apresenta moda granulométrica superior aos sedimentos observados na face de praia atual, o que pode significar um ambiente praial mais energético no passado. A Litofácies 2, conglomerática, corrobora essa interpretação, entretanto, o fato da praia atual não conter seixos e calhaus, e a paleopraia sim, pode representar apenas uma maior disponibilidade destes fragmentos no passado.

Por outro lado, foram encontrados grânulos e seixos de beachrock na areia da praia atual, mostrando que a erosão dos beachrocks contribui para os sedimentos da praia e que este processo se repetiu durante o Holoceno.

Em relação aos processos diagenéticos, os tipos de cimentação descritos nas litofácies 1 e 2 indicam precipitação de $\mathrm{CaCO}_{3}$ em zona freática marinha ativa, sob a ação de marés, correntes ou ondas. Cabe ressaltar que o estudo do processo de cimentação aqui realizado teve caráter preliminar, sendo ainda necessária petrografia mais aprofundada, bem como análises químicas e de microscopia eletrônica dos cimentos.

Destaca-se, também, a importância ecológica destes afloramentos e blocos, que criam ambientes propícios para elevada concentração de pescado e desenvolvimento de mexilhões, o que pode ter sido um atrativo para os sambaquieiros no passado como é para os pescadores atuais.

Finalmente, é inegável o enquadramento destas rochas como patrimônio geológico, seja pela sua importância histórica e cultural, seja pelas informações geológicas que ela pôde fornecer. A ocorrência se constitui como patrimônio geológico do tipo geomorfológico (paisagem), sedimentar (fácies e estruturas), paleoambiental 
(posicionamento de praia pretérita), petrológico (posicionamento do dique de diabásio), além de arqueológico (presença nos sambaquis). Por tudo isto e pela sua inserção no contexto da história da ciência (descrito por Charles Darwin em 1832), o sítio tem importância internacional e valor científico, cultural, didático e ecológico.

\section{Referências}

Assis H.M.B., Amaral R.F., Manso V.A.V. 1990. Caracterização dos "beach rocks" do litoral sul de Pernambuco com base em evidências petrográficas e isotópicas. In: SBG, Congresso Brasileiro de Geologia, 34, Anais, p. 635-646.

Bates R.L., Jackson J.A. 1987. Glossary of Geology. 3. ed., Alexandria, American Geological Institute, 788 p.

Blair T., McPherson J.G. 1999. Grain-size and textural classification of coarse sedimentary particles. Journal of Sedimentary Research, 69(1):6-19.

Brilha J. 2005. Património geológico e geoconservação: a conservação da natureza na sua vertente geológica. Braga, Palimage Editores, 190 p.

Carneiro C.F.A.G. 2007. A Constituição de Patrimônios Naturais e o Tombamento da Serra do Mar no Paraná. Tese de Doutorado, Universidade Federal do Paraná, Curitiba, 577 p.

Carvajal D.J., González A. 2003. La contribuición del patrimonio geológico y minero al desarrollo sostenible. In: Villas-Boas R.C., Martínez A.G., Albuquerque G.A.S.C. (eds.) Patrimonio Geológico y minero en el contexto del Cierre de Minas. Rio de Janeiro, CNPq/ CYTED, p. 27-49.

Castro J.W.A., Suguio K., Ramos R.R.C., Tenório M.C. 2009. Indicadores de oscilações do nível relativo do mar em Arraial do Cabo - Rio de Janeiro na transição entre o Pleistoceno e o Holoceno. In: ABEQUA, Cong. da ABEQUA, 12, Anais, p. 85.

Clifton H.E. 1969. Beach lamination: nature and origin. Marine Geol., 7:553-559.

Darwin C.R. 1832. Rio de Janeiro excursion city. M. Video Bahia Blanca. Beagle field Notebook. Disponível em: http://darwin-online.org.uk/content/frameset?itemID $=$ EH1.10\&viewtype $=$ text\&pageseq $=1$ Acessado em: 27/01/2010.

Darwin C.R. 1841. On a remarkable bar of sandstone off Pernambuco, on the coast of Brazil. Edimburgh and Dublin Philosophical Magazine, 19:257-260.

Darwin C.R. 1842. The structure and distribution of coral reefs. Being the first part of the geology of the voyage of the Beagle, under the command of Capt. Fitzroy, R.N. during the years 1832 to 1836 . London, Smith Elder and Co., $214 \mathrm{p}$.

Darwin C.R. 1844. Geological observations on the volcanic islands visited during the voyage of H.M.S. Beagle, together with some brief notices of the geology of Australia and the Cape of Good Hope. Being the second part of the geology of the voyage of the Beagle, under the command of Capt. Fitzroy, R.N. during the years 1832 to 1836. London, Smith Elder and Co., 648 p.

Darwin C.R. 1858. The autobiography of Charles Darwin 1809-1882. London, Collins, 250 p.
DRM - Departamento de Recursos Minerais. 1981. Mapa Geológico de Saquarema. SF-23-Z-B-V-4. Niterói, mapa geológico, escala 1:50.000.

Dias G.T.M., Gorini M.A., Gallea C.G., Espindola C.R.S., Mello S.M., Dellapiazza H., Castro J.R.J.C. 1982. Bancos de arenito de praia (beach rocks) submersos na Plataforma Continental SE Brasileira. In: SBG, Congresso Brasileiro de Geologia, 32, Anais, p. 1540-1546.

Dias G.T.M., Silva C.G. 1984. Geologia de depósitos arenosos costeiros emersos - exemplos ao longo do litoral fluminense. In: UFF, Simpósio sobre Restingas Brasileiras, 1, Anais, p. 47-60.

Francisco B.H.R. 1995. Ocorrência de seixos de arenitos de praia nos sambaquis do Moa e da Beirada e a variação do nível do mar no litoral de Saquarema (RJ). In: SBG, Cong. da ABEQUA, 5, Resumos, p. 42-45.

Francisco B.H.R. 1998. O Homem e a Geo-História da Região de Saquarema. Tese de Doutorado, Instituto de Geociências, Universidade Federal do Rio de Janeiro, Rio de Janeiro, 277 p.

Francisco B.H.R., Andrade W.A., Machado S. 1998. Arenito de praia de Jaconé (RJ) e sua relação com o material lítico dos sambaquis de Saquarema (RJ). In: SBG, Congresso Brasileiro de Geologia, 40, Anais, p. 417.

FreemanR.B. 1977.The Works ofCharles Darwin: anAnnotated Bibliographical Handlist. Disponível em: http:/darwinonline.org.uk/content/frameset?viewtype=text\&itemID= A1\&pageseq=1. Acessado em: 27/01/2010.

García-Cortés A.G. 1996. Inventario del Patrimonio Geológico. In: Ministerio de Obras Públicas, Transportes y Medio Ambiente, Sociedad Española de Geologia Ambiental y Ordenación del Territorio, Comissión de Patrimonio Geológico de la Sociedad Geológica de España (ed.). El Patrimonio Geológico. Bases para su valoración, protección, conservación y utilización. Madrid, Instituto Geológico y Minero de España, p. 53-60.

Hughen K., Baille M., Bard E., Beck J., Bertrand C., Blackwell P., Buck C., Burr G., Cutler K., Damon P., Edwards R., Fairbanks R., Friedrich M., Guilderson T., Kromer B., McCormac F., Manning S., Bronk-Ramsey C., Reimer P., Reimer R., Remmele S., Southon J., Stuiver M., Talamo S., Taylor F., der Plicht J., Weyhenmeyer C. 2004. Marine04: Marine radiocarbon age calibration, 26 - 0 ka BP. Radiocarbon, 46(3):1059-1086.

Kelletat D. 2006. Beachrock as sea-level indicator? Remarks from a geomorphological point of view. Journal of Coastal Research, 22(6):1558-1564.

Longman M.W. 1980. Carbonate diagenetic textures from nearsurface diagenetic environments. The American Association of Petroleum Geologists Bulletin, 64:461-487. 
Macedo A.C.M. 1971. Testemunhos geológicos da evolução do litoral no Estado da Guanabara. Anais da Academia Brasileira de Ciências, 43(3/4):832.

Mansur K.L., Brito F., Nascimento V.M.R., Ramos R.R.C. 2009. Uma exposição de rochas e minerais para divulgação da história da ciência e para o conhecimento: a Geologia no trajeto de Charles Darwin no Estado do Rio de Janeiro. In: SBG, Simp. Geol. Sudeste, 11, Anais, p. 116.

Martins L.R., Urien C.M., Martins I.R. 2005a. Gênese dos sedimentos da Plataforma Continental Atlântica entre o Rio Grande do Sul (Brasil) e Tierra del Fuego (Argentina). Gravel, 3:85-102.

Martins L.R., Martins I.R. \& Urien C.M. 2005b. Sand Bodies of the Santa Catarina Inner Continental Shelf, Brazil. Gravel, 3:103-108.

McCubbin D.G. 1982. Barrier Islands and Strand-Plain Fácies. In: Scholle P.A., Spearing D. (eds.). Sandstone Depositional Environments. Tulsa, AAPG, p. 247-279.

Moreira I.C., Brito M.F., Mansur K.L. 2009. Darwin - um roteiro turístico, educacional e científico no estado do Rio de Janeiro, Brasil. In: USP, Simpósio de Pesquisa em Ensino e História de Ciências da Terra, 2, Anais, 1 CD-Rom.

Muehe D., Ignarra S. 1984. Arenito de praia submerso em frente à praia de Itaipuaçu - RJ. In: SBG, Congresso Brasileiro de Geologia, 33, Anais, p. 341-348.

Muehe D., Valentini E. 1998. O Litoral do Estado do Rio de Janeiro: uma caracterização físico-ambiental. Rio de Janeiro, Fundação de Estudos do Mar, 96 p.

Muehe D., Lima C.F., Lins-de-Barros F.M. 2007. Erosão e Progradação do Litoral Brasileiro: Rio de Janeiro. In: Programa de Geologia e Geofísica Marinha (eds.) Erosão e Progradação do Litoral Brasileiro. Brasília, Ministério do Meio Ambiente, p. 267-296.
Oliveira M.I.M., Bagnolli E., Farias C.C., Nogueira A.M.B., Santiago M. 1990. Considerações sobre a geometria, petrologia, sedimentologia, diagênse e idades dos beachrocks do Rio Grande do Norte. In: SBG, Cong. Bras. Geologia, 34, Anais, p. 621-634.

Russel R.J. McIntire W.G. 1965. Beach cusps. Geol. Soc. Am. Bull. 76:307-320.

Savi D.C., Tenório M.C., Calippo F.R., Toledo F.A.L., Gonzalez M.M.B., Afonso M.C. 2005. Beachrock e o Sambaqui da Ilha do Cabo Frio. In: ABEQUA, Cong. da ABEQUA, 10, Resumos, p. 29.

Stuiver M., Reimer P.J. 1993. Extended ${ }^{14} \mathrm{C}$ Data Base and Revised Calib 3.014c Age Calibration program. Radiocarbon, 35(1):215-230.

Vieira M.M., De Ros L.F. 2006. Cementation patterns and genetic implications of Holocene beachrocks from northeastern Brazil. Sedimentary Geology, 192(2006):207-230.

Vieira M.M., De Ros L.F., Bezerra F.H.R. 2007. Lithofaciology and palaeonvironmental analysis of Holocene beachrocks in Northeastern Brazil. Journal of Coastal Research, 23(6):1535-1548.

Vousdoukas M.I., Velegrakis A.F., Plomaritis T.A. 2007. Beachrock occurrence, characteristics, formation mechanisms and impacts. Earth-Science Reviews, 85:23-46.

U.S. ARMY CORPS OF ENGINEERS. 1995. CECWEG Engineer Manual 1110-2-1810: Coastal Geology. Whashington, 1995.

Manuscrito ID 16799

Submetido em 09 de fevereiro de 2010 Aceito em 04 de outubro de 2011 